\title{
Is value statement an effective informal control for stimulating pro-environmental behaviors?*
}

\author{
Andson Braga de Aguiar ${ }^{1}$ \\ (D) https://orcid.org/0000-0003-4034-4134 \\ Email: abraga@usp.br \\ ${ }^{1}$ Universidade de São Paulo, Faculdade de Economia, Administração e Contabilidade, Departamento de Contabilidade e Atuária, São Paulo, SP, \\ Brazil
}

Received on 02.03.2020 - Desk acceptance on 02.12.2020 - $4^{\text {th }}$ version approved on 05.01.2020 - Ahead of print on 11.27.2020

Editor-in-Chief: Fábio Frezatti

Associate Editor: Cláudio de Araújo Wanderley

\begin{abstract}
This study aimed to examine when and how a pro-environmental value statement is effective at stimulating pro-environmental behavior. Specifically, it examines whether the effect of pro-environmental value statements on pro-environmental behavior depends on participation in goal setting and whether that effect is explained by goal commitment. Few recent empirical studies examine the behavioral effects of value statements, despite the potential of this informal control to stimulate appropriate behaviors. Also scarce are studies on management control examining the effects of different types of control on pro-environmental behavior. Pro-environmental behaviors are important in the business environment as they promote a reduction in pollutants and contribute to the effective design of environmental management systems and to environmental performance. Thus, it is important to identify how management control mechanisms can promote or inhibit this type of behavior. The contribution to the management control literature is to show in which context and through which process value statements can be an effective informal control. In addition, the practical implication is that decentralized organizations can benefit from the use of value statements as a control mechanism, providing they enable participation in goal setting. Participants were recruited via the Amazon Mechanical Turk platform and they had to decide about compliance with an environmental agreement in an experimental study. I manipulate the presence of a pro-environmental value statement and the participation in setting the profit goal. Research findings indicate that a pro-environmental value statement reduces commitment to the profit goal and thus increases environmental compliance, but only when the goal-setting is participative. When the goal-setting is imposed, a pro-environmental value statement does not affect commitment and environmental compliance. The main contribution is to indicate that decentralized organizations can stimulate appropriate behaviors by communicating prioritized values through a value statement when participation in goal setting is allowed.
\end{abstract}

Keywords: value statement, participative goals, goal commitment, environmental compliance, pro-environmental behavior.

Correspondence address

Andson Braga de Aguiar

Universidade de São Paulo, Faculdade de Economia, Administração e Contabilidade, Departamento de Contabilidade e Atuária

Avenida Professor Luciano Gualberto, 908 - CEP 05508-010

Cidade Universitária - São Paulo - SP - Brazil

*The author is grateful to the Institute of Management Accountants for the financial support to carry out this research. 


\section{INTRODUCTION}

This study examines when and how a proenvironmental value statement acts as an effective informal control for stimulating pro-environmental behaviors. Pro-environmental behavior is when an individual carries out actions that contribute to environmental sustainability (Ones et al., 2015). It is a topic of much concern for organizations (Bansal \& Roth, 2000), including the Brazilian context (Santos, 2017). From a managerial control perspective, larger-sized organizations usually decentralize the decision-making process to make achieving pro-environmental goals viable and empower managers (Church et al., 2019). In such cases, top executives determine and communicate the pro-environmental strategy and give autonomy to middle-level managers to execute that strategy, including autonomy to allocate resources (Church et al., 2019). This study emphasizes autonomy in the execution of pro-environmental actions and examines managers' compliance with an environmental agreement (i.e. environmental compliance).

Organizations can use formal and/or informal controls to induce appropriate behaviors (Berry et al., 2009; Malmi $\&$ Brown, 2008). Typically, greater attention has been given to the role of formal controls to align behaviors, even though informal controls can also be an effective management control for inducing appropriate behaviors (Andrejkow et al., 2019; Berry et al., 2009). This study emphasizes managers' decision-making process, in which there is an informal control in the form of a proenvironmental value statement that prioritizes respecting and appreciating the environment, where environmental compliance goes against the economic interests of managers and the organization.

Value statement is an important informal control when communicated by executives to the different hierarchical levels (Collis \& Rukstad, 2008; Marginson, 2009). The prioritized values in the value statement indicate the behaviors that an organization considers appropriate (Kachelmeier et al., 2016). So, a pro-environmental value statement stimulates managers to direct their attention to information associated with those values, thus making it more likely that those managers will adopt pro-environmental behaviors (Verplanken \& Holland, 2002). While it may be an effective informal control (Andrejkow et al., 2019), the behavioral effect of a value statement will more likely occur as an interaction with formal controls (Kachelmeier et al., 2016).

An important formal control for giving autonomy to managers in the decision-making process and empowering them is participation in the process of setting financial goals (Spreitzer, 1996; Van der Kolk et al., 2015). Organizations can set goals in an imposed or participative way (Arnold, 2015; Fisher et al., 2003). Goal-setting participation has implications for managers' behavior, specifically in terms of their level of commitment to those goals (Locke et al., 1981).

The central argument of this study is that a proenvironmental value statement is an effective informal control as it reduces the commitment to achieving financial goals and thus stimulates environmental compliance, but only when the managers participate in the goal setting. Thus, the final effect of a value statement on pro-environmental behavior depends on how the financial goals are set, whether in a participative or imposed way. In particular, I expect that managers who receive a pro-environmental value statement and participate in setting a financial goal are probably less committed to that goal and, consequently, to increase environmental compliance. On the other hand, when the financial goal is imposed, the same effect of the pro-environmental value statement is not expected; in this case, I expect that managers tend not to alter their commitment to achieving the goal and, therefore, a pro-environmental value statement should not affect environmental compliance for those managers.

To examine the behavioral effects of value statements, I adapt the experimental task in Tenbrunsel and Messick (1999), in which participants indicate compliance or not with an environmental agreement. I manipulate the pro-environmental value statement (present versus absent) and participation in goal setting (imposed versus participative).

Consistently with the expectations of this study, the results indicate the presence of an interactive effect between the pro-environmental value statement and participation in setting the profit goal on commitment to that goal. The results also indicate that less commitment to the profit goal increases environmental compliance. Finally, a mediation analysis offers support for the central argument of this study that a pro-environmental value statement reduces commitment to the profit goal and thus stimulates environmental compliance, but only when the profit goal is participative.

Next, the research hypotheses are developed, the context of the experiment is described, the results are analyzed, and the main implications and limitations are discussed. 


\section{THEORETICAL FRAMEWORK AND HYPOTHESES DEVELOPMENT}

\subsection{Pro-Environmental Behavior}

Pro-environmental behavior is when an individual deliberately carries out actions that contribute to environmental sustainability (Coelho et al., 2006; Ones et al., 2015). Individuals who adopt this behavior benefit the environment or at least avoid causing environmental damage, preferring actions that result in collective benefits, even if at the cost of not obtaining personal benefits (Clark et al., 2003; Steg \& Vlek, 2009). Pro-environmental behavior is a topic of much concern for the business context (Bansal \& Roth, 2000), as pro-environmental actions reduce pollutant emissions, contribute to the use of more efficient environmental management systems, and favor environmental performance (Paillé \& Boiral, 2013). For these reasons, organizations increasingly promote pro-environmental initiatives (Ones et al., 2015).

While studies on the determinants of pro-environmental behaviors are common in areas such as environmental psychology [e.g., Paillé and Boiral (2013) and Steg and Vlek (2009)], they remain scarce in the managerial control literature. This literature usually emphasizes one type of behavior that, although associated, is broader and relates to corporate social responsibility actions [e.g., Church et al. (2019) and Rodgers et al. (2015)]. However, such studies typically adopt a perspective of investigating determinants and impacts of financial disclosure with information about corporate social responsibility (Dhaliwal et al., 2011, 2012).

This article broadens the scope of studies on determinants of pro-environmental behaviors by examining effects of management control mechanisms on middle-level managers' pro-environmental behaviors. In larger-sized organizations, pro-environmental initiatives are usually decentralized, aiming to make the decision-making process more efficient and empower managers (Church et al., 2019; Maclagan, 1999). When pro-environmental initiatives are decentralized, middlelevel managers have the autonomy to carry out such initiatives, particularly in terms of allocating resources (Church et al., 2019).

When managers have decision-making autonomy and top executives observe only the effects of the actions carried out, the managers can act strategically and make choices that bring them personal benefits instead of executing pro-environmental actions (Guth \& MacMillan, 1986; Tenbrunsel \& Messick, 1999). To deal with agency problems such as these and align interests, organizations use management control systems (Malmi \& Brown, 2008; Merchant \& Van der Stede, 2012), especially formal controls (Berry et al., 2009). However, formal controls (e.g., monitoring and incentive schemes) are usually ineffective for stimulating pro-social behavior (Christ et al., 2008; Tenbrunsel \& Messick, 1999). In this study, as will be developed below, I propose an alternative form of management control to stimulate pro-environmental behaviors.

\subsection{Value Statement as an Informal Control Mechanism}

The literature on organizational values has a long tradition and ranges from examining personal values typologies [e.g., Schwartz (1992)] to emphasizing the fit between personal and organizational values [e.g... Chatman (1991)]. Also standing out are studies that highlight how organizational values are actually perceived by managers [e.g. Tamayo (1998)]. In this study, I examine the topic from the perspective of their use as a management control through their communication in the form of a value statement.

As part of the value system, a value statement is seen as an essential component of management control and performance management systems (Ferreira \& Otley, 2009; Malmi \& Brown, 2008). In particular, a value statement is a type of informal control that communicates what an organization values and prioritizes and thus stimulates appropriate behaviors via self-regulation (Christ et al., 2008; Kachelmeier et al., 2016; Marginson, 2009; Ouchi, 1979).

Studies emphasizing the behavioral effects of a value statement are recent and generally indicate that managers behave in accordance with the values prioritized in the statement [e.g., Andrejkow et al. (2019)]. For example, Kachelmeier et al. (2016) indicate that the participants in their experiment change production strategy when a value statement is present and go on to behave in accordance with the communicated values. This result occurs even in the presence of a performance-based compensation that is higher when the participants adopt a production strategy not prioritized in the value statement. Akinyele et al. (2020) confirm this result and also indicate that the behavioral effects of the value statement increase if the communication is frequent. 
In summary, empirical evidence supports the expectation that the behavioral effect of a value statement depends on the values prioritized in the statement (Marginson, 2009; Simons, 1995). So, the communication of a pro-environmental value statement guides managers' attention to the information associated with those values, increasing the chances of pro-environmental behaviors being adopted (Verplanken \& Holland, 2002). In this sense, a pro-environmental value statement can be an effective informal control for stimulating proenvironmental behaviors. However, the effect of a value statement is more likely to occur as an interaction with formal controls (Kachelmeier et al., 2016). As developed below, a particularly important formal control mechanism in decentralized organizational contexts is the level of participation in goal setting.

\subsection{Participation in Financial Goal Setting}

Participation in the decision-making process indicates a joint action in which subordinates and superiors share information and it can be an effective management tool for increasing job satisfaction and performance (Lam et al., 2002; Spector, 1986). While participation can occur in relation to different decision-making aspects, this study is interested in the participation that occurs (or not) in setting financial goals. In decentralized organizations, participation in the process of setting financial goals is an important formal control that increases the decisionmaking autonomy and empowerment of managers (Spreitzer, 1996; Van der Kolk et al., 2015).

Participation in goal-setting involves situations in which goals are unilaterally set by higher-level managers and imposed on subordinate managers, as well as situations in which there is some level of joint action between superiors and subordinates for setting the goals (Arnold, 2015; Fisher et al., 2003). The behavioral effects of financial goal setting depend on whether that goal is participative or imposed (Chang \& Lorenzi, 1983). In particular, whether the financial goal setting is participative or not affects how much effort the managers make to achieve that goal, i.e., the level of goal commitment (Locke et al., 1981).

Various studies examine the effect of participation in the setting of financial goals on goal commitment in a budgetary context [e.g., Chong and Chong (2002) and Nouri and Parker (1998)]. These studies generally suggest that greater goal-setting participation increases goal commitment, which in turn influence different aspects of managers' behavior [e.g., Chong et al. (2006) and Maiga (2005)]. In turn, the literature on motivation at work indicates that the effects of the level of participation on goal commitment depend on the context (Klein \& Joseph, 2013; Locke et al., 1988). In particular, as will be developed below, I propose that the effect of participation in setting a profit goal on the commitment to that goal depends on the presence or not of a pro-environmental value statement.

\subsection{Interactive Effects on Commitment to the Profit Goal}

The central argument of this study is that a proenvironmental value statement is an effective informal control, as it reduces commitment to the financial goals and thus stimulates environmental compliance, but only when the goals are participative. The first hypothesis predicts the effect of a pro-environmental value statement on the commitment to the profit goal for different levels of participation in the goal-setting; in turn, the second hypothesis predicts the effect of the level of commitment on environmental compliance.

As already mentioned, managers can participate in setting financial goals or have those goals imposed (Arnold, 2015; Fisher et al., 2003). Managers who participate in the goal-setting have greater decision-making autonomy; that is, they can plan and control how and when to carry out certain actions (Spector, 1986). Moreover, these managers understand that is possible to transfer that autonomy between contexts (Van der Kolk et al., 2015), such as when autonomy in setting the profit goal is transferred to autonomy over whether that goal should be prioritized if it enters into conflict with another goal, such as a proenvironmental one.

Thus, a value statement that prioritizes proenvironmental goals can generate a conflict with the achievement of financial goals by driving the attention of managers with decision-making autonomy to information associated with the prioritized values (Verplanken \& Holland, 2002). In a context in which there is a conflict between the profit goal and behaviors consistent with the prioritized values, managers with greater decisionmaking autonomy may deviate from the profit goal by reducing their commitment to achieving that goal, even if doing this reduces personal benefits. In these cases, a pro-environmental value statement can be effective in stimulating appropriate behaviors by making those managers reduce their level of commitment to the profit goal, which would be the same as saying that they increase their level of commitment to the goal linked to the prioritized values.

In turn, managers whose profit goal is imposed by higher-level managers do not have decision-making 
autonomy (Spector, 1986). Specifically, these managers tend not to deviate from the goal imposed and, as a result, do not drive their attention to information associated with the prioritized values in a pro-environmental value statement. Thus, the managers whose profit goal is imposed maintain their level of commitment to that goal, whether a pro-environmental value statement is present or not. Therefore, in these cases, a pro-environmental value statement tends to be less effective at stimulating appropriate behaviors and does not encourage managers to reduce their level of commitment to the profit goal.

In summary, a pro-environmental value statement will affect commitment to a profit goal, but that effect will be different depending on how the goal is set. When imposed, a pro-environmental value statement is less effective at explaining goal commitment. In these cases, the managers will maintain their levels of commitment to the profit goal, whether a pro-environmental value statement is present or not. On the other hand, a pro-environmental value statement is an effective informal control for driving the attention of managers who participate in goal setting, making them reduce their commitment to the profit goal in favor of the goal linked to the prioritized values. Specifically, the first hypothesis of this study predicts that a pro-environmental value statement reduces the level of commitment to the profit goal when that goal is participative, not when it is imposed. Formally, the first hypothesis of this study is elaborated as follows:

$\mathrm{H}_{1}$ : relative to its absence, the presence of a pro-environmental value statement reduces the level of commitment to the profit goal, but only when the managers participate in the goal-setting.

\subsection{Commitment to Financial Goals and Environmental Compliance}

The literature on goal setting shows that the main effect of goal commitment is on task performance (Klein
\& Joseph, 2013; Latham \& Locke, 1991). A similar effect is shown by studies on management control that examine goal commitment in budgetary contexts [e.g., Chong and Chong (2002) and Wentzel (2002)]. Commitment to a profit goal will affect managers' performance in executing actions needed to comply with an environmental agreement. In particular, when there is a conflict between a financial goal and an environmental one, less commitment to the financial goal implies a greater likelihood of commitment to the environmental goal, and vice-versa. Therefore, a negative effect is expected of commitment to a profit goal on environmental commitment, particularly when the managers participate in the goal-setting.

In summary, managers with low levels of commitment to the financial goal will tend to adopt pro-environmental behaviors and thus increase environmental compliance. Consistently with the first hypothesis, this expectation is particularly valid for when the managers participate in the goal-setting, but not when that goal is imposed. In particular, the second hypothesis of this study predicts that environmental compliance will be greater when the level of commitment to the profit goal is lower, but only when the managers participate in goal-setting. Formally, the second hypothesis of this study is elaborated as follows:

$\mathrm{H}_{2}$ : a lower level of commitment to the profit goal increases environmental compliance, but only when the managers participate in the goal-setting.

Considered together, the two hypotheses of this study suggest that the effect of a pro-environmental value statement on environmental compliance only occurs when there is participation in setting a profit goal and that this effect is mediated by the level of compliance with that goal, so that the presence of a value statement reduces the level of commitment to the profit goal and thus increases environmental compliance, but only when the managers participate in the goal-setting.

\section{EXPERIMENTAL DESIGN}

The hypotheses of this study are tested in the context of a social dilemma in which participants indicate their compliance or not with an environmental agreement. In this context, there is a trade-off between personal/ organizational benefits and social benefits (Dawes, 1980; Dawes \& Messick, 2000). This means that compliance has positive environmental effects, but reduces the organization's profits, preventing the profit goal from being achieved. A $2 \times 2$ between-participants experimental design is used, with two manipulated variables: proenvironmental value statement and participation in setting the profit goal. 


\subsection{Experimental Task}

The experimental task is adapted from Tenbrunsel and Messick (1999). Participants assume the role of managers of a medium-sized industrial plant. They are informed that the manufacturers in this industry face a problem with emissions of a toxic gas - VS-1 - generated during the production process. Environmentalists are concerned about the problem and propose that all smokestacks are equipped with scrubbers that eliminate the toxic gas if they are activated $100 \%$ of the production time. With the potential threat of environmentalists seeking to influence the approval of legislation that imposes the use of scrubbers $100 \%$ of the time, the manufactureers in the industry get together and reach the conclusion that everyone will install the scrubbers and operate them $80 \%$ of the time. This solution is acceptable to the environmentalists and avoids the legislation that would impose an estimated cost of compliance of 3 million liras (experimental currency).

The participants have two options. One is compliance with the environmental agreement through the installation and operation of the scrubbers for $80 \%$ of the time, which would result in an estimated cost of 1.2 million liras. The other is non-compliance, in which the scrubbers would be operated less than $80 \%$ of the time. In this case, the estimated cost depends on the total time that the scrubbers remain active, with each interval of $20 \%$ of the time costing 0.3 million liras: activating them $20 \%$ of the time will cost 0.3 million liras; operating them $40 \%$ of the time will cost 0.6 million liras, and so on. Table 1 presents the four potential outcomes.

Table 1

Potential outcomes

\begin{tabular}{ccccc}
\hline $\begin{array}{c}\text { Time of operation of } \\
\text { the scrubbers } \mathbf{( \% )}\end{array}$ & Legislation & \multicolumn{3}{c}{ Costs (currency: lira) } \\
\cline { 3 - 5 } & No & Operational & Compliance & 0 \\
\hline 80 & No & $\begin{array}{c}0-900,000 \\
(0-60 \% \text { of operation) }\end{array}$ & 0 & $0-900,000$ \\
\hline 80 & Yes & $1,200,000$ & $3,000,000$ & $4,200,000$ \\
\hline$<80$ & Yes & $\begin{array}{c}0-900,000 \\
(0-60 \% \text { of operation) }\end{array}$ & $3,000,000$ & $3,000,000-3,900,000$ \\
\hline
\end{tabular}

Source: Tenbrunsel and Messick (1999).

The participants are informed that all the manufacturers in the industry are faced with the same decision. The costs of compliance derived from the legislation will be avoided only if most fulfill the environmental agreement; otherwise, the legislation will be approved and the compliance costs will be imposed on all the manufacturers. The participants are also informed that their perception regarding the approval of the legislation depends on the expectation that they have concerning the decision of the other manufacturers in the industry. So, if the expectation is that most will fulfill the environmental agreement, the legislation is not expected to be approved; however, if the expectation is that most will not fulfill the agreement, the legislation is expected to be approved. In this scenario, the participants indicate the percentage of time they intend to operate the scrubbers, capturing a trade-off between financial returns and environmental respect.

\subsection{Variables Manipulation}

Pro-environmental value statement is manipulated at two levels: present and absent. In both cases, the participants receive a newsletter communicating the recent participation of the chief executive officer in an environmental conference. In the condition that there is a pro-environmental value statement, the following additional information is included at the top of the newsletter regarding the organization's prioritized values: "Our company respects and values the environment." In the condition in which no communication occurs, the participants receive the newsletter without the additional information about the organization's prioritized values.

Participation in setting the profit goal is also manipulated at two levels: imposed and participative. After reading the newsletter, the participants in the condition in which the goal is imposed read that "The profit goal set by the chief executive officer is 900 thousand liras." The participants in the participative goal condition read that "The profit goal set participatively between you and the chief executive officer is 900 thousand liras." The participants are also informed that their compensation includes a fixed portion worth 30 thousand liras plus a bonus of 15 thousand liras to only be earned if the profit goal is achieved or exceeded. Thus, non-achievement of the profit goal has implications both for the organization, which will not achieve its profit goal, and for the participants, who will not receive the bonus tied to achieving the goal. 


\subsection{Participants and Procedures}

Participants were recruited via the Amazon Mechanical Turk (MTurk) platform, which is accessed via a user's account on Amazon. MTurk enables quick and low cost access to high quality data (Buhrmester et al., 2016). However, they may have distortions derived from the inclusion of false information (e.g., identity) and from inattention in the answers provided (Fleischer et al., 2015; Wessling et al., 2017). To deal with potential biases in the use of MTurk, it is recommended that participants with higher intelligence scores are chosen (Buchheit et al., 2019). In this study intelligence scores are higher than $90 \%$. In general, the data obtained via MTurk are as reliable as those obtained through traditional methods (Buhrmester et al., 2016).

Of a total of 136 participants, eight are excluded due to an incomplete form (five) and similar IPs (three). For the other 128 participants, the mean age is 39.4 years and the mean work experience is 17.3 years. More than $83 \%$ of the participants have already been faced with situations in which they had to choose between obtaining personal benefits and preserving the environment. Of the participants, $53.2 \%$ are women and $77.8 \%$ have at least a graduate level education. The participants are generally considered adequate for the purposes of this study as they are familiar with the business environment and with situations in which they need to weigh up the environmental implications in the decision-making process.

The experimental procedures are the same in all the conditions. The participants access a link in MTurk that takes them to the Qualtrics ${ }^{\circledR}$ platform, in which the research form is elaborated. The Qualtrics ${ }^{\circledR}$ platform is responsible for carrying out the randomization between the experimental conditions. Before accessing the experimental task, the participants read a consent form and indicate their agreement to participate in the research, the general instructions regarding their role in the experiment, and the sequence of the form.

First, the participants read specific instructions about the environmental agreement and the possible effects on the organization's profit if the decision is one of compliance or not with the agreement. They also read about the sanctioning system, if the environmental agreement is not fulfilled, and the profit estimate before the decision. In particular, the participants are informed that the representatives of the sector will conduct unscheduled visits to the manufacturers. It is estimated that the probability of a specific manufacturer being inspected is less than $5 \%$ and, if inspectd and found that the scrubbers operate less than $80 \%$ of the production time, the fine is perceived as negligible, at 50 thousand liras. This sanctioning system is similar to one of the experimental conditions in Tenbrunsel and Messick (1999) and characterized as weak.

The participants are informed that the profit estimate is 2 million liras before the costs of operating the scrubbers. Thus, if the participants fulfill the environmental agreement and incur the additional operating costs of operating the scrubbers, the organization's profit will decrease to 800 thousand liras. In this case, the profit goal of 900 thousand liras will not be achieved and, as a result, the participants will only receive the fixed portion of their compensation. With this, the participants are faced with a trade-off between fulfilling the environmental agreement and environmental respect, on one hand, and fulfilling the organization's goal and obtaining financial benefits, on the other hand.

Next, the participants answer coomprehension questions to check their understanding of the general instructions. Eight participants are excluded for failing to indicate the main implications of not fulfilling the environmental agreement, and so the number of valid participants is 120 . After the comprehension questions, the manipulations are introduced and the participants decide how long to operate the scrubbers, capturing compliance or not with the environmental agreement, this being the dependent variable to test the second hypothesis of this study. In the analysis, the participants who indicate operating the scrubbers for at least $80 \%$ of the time are coded 1 (compliance) and 0 (non-compliance) otherwise.

Next, the participants use a 7-point Likert scale (1, totally disagree; 7 , totally agree) to answer the five items that capture compliance with the profit goal (Webb, 2004). The items are: (i) I would care about achieving the profit goal; (ii) I would be unlikely to stop pursuing the profit goal; (iii) I think that the profit goal would be a good goal to strive for; (iv) I would be extremely committed to achieving the profit goal; and (v) I would be willing to put in a great deal of effort to achieve the profit goal. A measure of commitment is created using principal components analysis. The items are grouped into a single factor with an eigenvalue of 3.64 that explains $73 \%$ of the variance. Goal commitment is the dependent variable in the first hypothesis and the independent variable in the second hypothesis.

The participants also answer nine questions that capture their social value orientation (Van Lange et al., 1997). When they answer six or more of these questions consistently, the participants are classified into three groups: individualists (31), competitors (2), or prosocial (70); otherwise, they are classified as inconsistent (17) and excluded from the analysis. With that exclusion, the final number of valid participants is 103 . For the analysis, the individualists and competitors are added together and called selfish (Van Lange et al., 1997). The social value orientation is included as a control variable in the main analyses. 
The participants then answer the demographic questions. At the end, they are informed about the amount of compensation they have earned and receive a code to enter into the MTurk platform to receive the compensation.
The mean compensation per participant is US $\$ 1.53$ for 120 participants with valid answers, besides US $\$ 2.18$ per participant, paid for the use of the MTurk platform. On average, the experimental task lasts 8.8 minutes.

\section{RESULTS}

\subsection{Descriptive Analysis}

Table 2 and Figure 1 present the descriptive statistics by pro-environmental value statement and participation in setting the profit goal. Commitment to the profit goal is the dependent variable, represented by the factor created in the principal components analysis: higher values indicate higher levels of commitment. Commitment is greater when the profit goal is participative and the pro-environmental value statement is absent (0.65), while commitment is lower when the profit goal is again participative and the pro-environmental value statement is present $(-0.44)$.

Table 2

Descriptive analysis: commitment to the profit goal

\begin{tabular}{|c|c|c|c|}
\hline Value statement & Imposed goal & Participative goal & Total \\
\hline \multicolumn{4}{|l|}{ Absent } \\
\hline Mean & -0.12 & 0.65 & 0.29 \\
\hline Standard deviation & 0.38 & 0.29 & 0.24 \\
\hline Number of participants & 25 & 29 & 54 \\
\hline \multicolumn{4}{|l|}{ Present } \\
\hline Mean & 0.25 & -0.44 & -0.06 \\
\hline Standard deviation & 0.34 & 0.46 & 0.28 \\
\hline Number of participants & 27 & 22 & 49 \\
\hline \multicolumn{4}{|l|}{ Total } \\
\hline Mean & 0.07 & 0.18 & 0.12 \\
\hline Standard deviation & 0.25 & 0.27 & 0.18 \\
\hline Number of participants & 52 & 51 & 103 \\
\hline
\end{tabular}

Source Elaborated by the author.

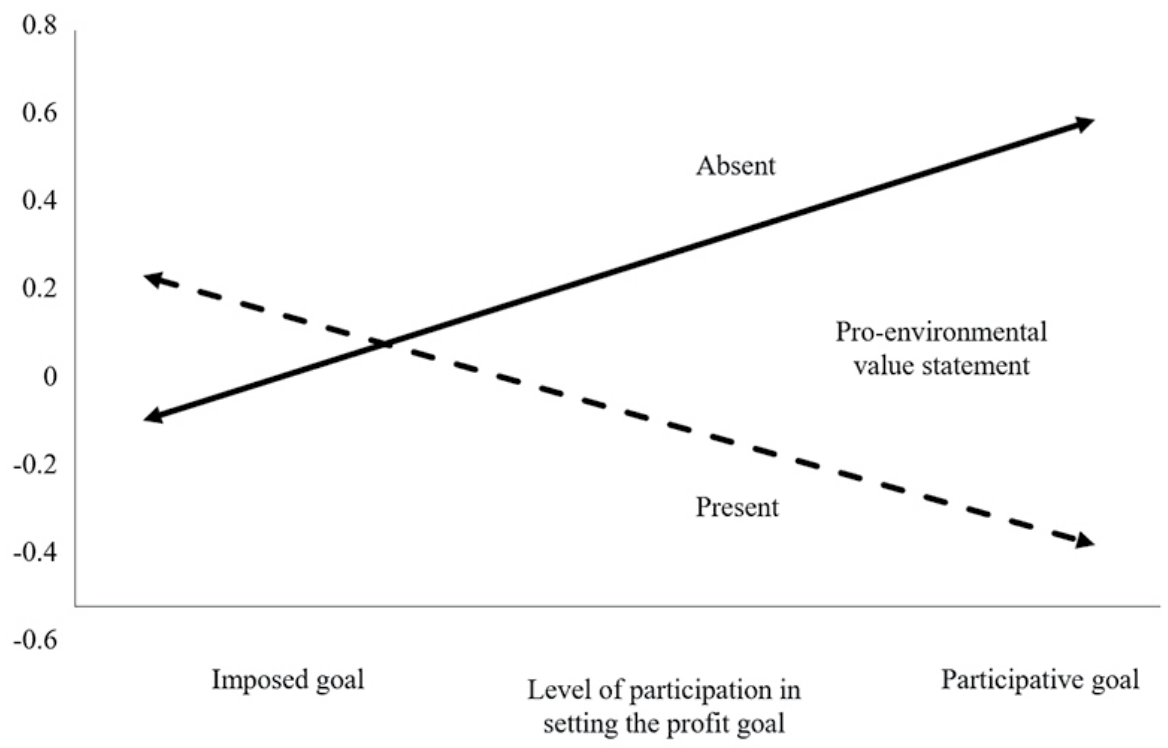

Figure 1 Commitment to the profit goal by pro-environmental value statement (present versus absent) and level of participation in setting the profit goal (participative versus imposed)

Source: Elaborated by the author. 
Table 3 indicates the descriptive statistics by level of commitment. The participants are separated into two groups based on the median (0.29) of the level of goal commitment: participants above the median are classified as 1 (high level) and 0 (low level) otherwise. The dependent variable is environmental compliance measured as the percentage of participants that indicates operating the scrubbers for at least $80 \%$ of the production time (compliance) or for less than $80 \%$ (non-compliance). A higher percentage of compliance occurs when goal commitment is low $(63.3 \%)$, while a lower percentage also occurs when the goal commitment is low (36.7\%).

Table 3

Descriptive analysis: compliance with the environmental agreement

\begin{tabular}{|c|c|c|c|}
\hline & \multicolumn{2}{|c|}{ Commitment to the profit goal } & \multirow{2}{*}{$\begin{array}{c}\text { Total } \\
(\%)\end{array}$} \\
\hline & Low $(\%)$ & High (\%) & \\
\hline Environmental compliance (participants) & $63.3(31)$ & $50.0(27)$ & $56.3(58)$ \\
\hline Non environmental compliance (participants) & $36.7(18)$ & $50.0(27)$ & $43.7(45)$ \\
\hline Total & $100.0(49)$ & $100.0(54)$ & $100.0(103)$ \\
\hline
\end{tabular}

Note: The percentages present the proportion of respondents that indicates compliance or not with the environmental agreement for low versus high level of commitment to the profit goal. For example, of the total respondents with a low level of commitment, $63.3 \%$ (31 respondents) indicate environmental compliance.

Source: Elaborated by the authors.

\section{2 $\mathrm{H}_{1}$ : Interactive Effects on Commitment to the Profit Goal}

The first hypothesis $\left(\mathrm{H}_{1}\right)$ of this study predicts that, in relation to its absence, the presence of a pro-environmental value statement reduces the level of commitment to the profit goal, but only when the managers participate in the goal-setting. To test $\mathrm{H}_{1}$, an analysis of variance (ANOVA) is initially conducted with level of goal commitment as the dependent variable and pro-environmental value statement, participation in the goal-setting, and interaction between these two variables as independent variables. Social value orientation is also included to control any possible predisposition of participants to favor prosocial actions. Panel A of Table 4 indicates that the interaction between pro-environmental value statement and participation in goal setting is statistically significant $(F=4.70$; one-tailed $p=0.016)$. It is also noted that social value orientation has a statistically significant effect $(\mathrm{F}=3.81$; two-tailed $\mathrm{p}=0.020)$ on commitment. In particular, commitment to the profit goal is greater for participants with a selfish value orientation (0.71) than for those with a prosocial value orientation $(-0.15)$.

Table 4

Analysis of variance (ANOVA) (dependent variable $=$ commitment to the profit goal)

\begin{tabular}{|c|c|c|c|c|}
\hline Factors & df & MS & $\mathbf{F}$ & p-value \\
\hline \multicolumn{5}{|l|}{ Panel A } \\
\hline Pro-environmental value statement (present versus absent) & 1 & 3.67 & 1.13 & 0.291 \\
\hline Participation in setting the profit goal (imposed versus participative) & 1 & 0.09 & 0.03 & 0.868 \\
\hline Interaction & 1 & 15.30 & 4.70 & $0.016^{* *}$ \\
\hline Social value orientation & 1 & 18.13 & 5.57 & $0.020^{* *}$ \\
\hline Error & 3 & 3.25 & & \\
\hline \multicolumn{5}{|l|}{ Panel B } \\
\hline Pro-environmental value statement for imposed goal & 1 & 1.97 & 0.59 & 0.224 \\
\hline Pro-environmental value statement for participative goal & 1 & 17.08 & 5.39 & $0.012^{* *}$ \\
\hline Goal-setting participation for present value statement & 1 & 7.31 & 2.44 & $0.062^{*}$ \\
\hline Goal-setting participation for absent value statement & 1 & 9.50 & 2.68 & $0.054^{*}$ \\
\hline
\end{tabular}

$d f=$ degrees of freedom; $M S=$ mean square.

$*, * *=10$ and $5 \%$ significance, respectively.

Source: Elaborated by the author. 
To obtain a more complete understanding about the interaction between pro-environmental value statement and participation in setting the profit goal, the differential effects of the pro-environmental value statement on goal commitment are examined for participants whose goal is imposed versus participative. Panel B of Table 4 indicates that the participants whose goal is participative are significantly less committed to the profit goal in the presence of the value statement than in its absence $(\mathrm{F}=5.39$; one-tailed $\mathrm{p}=0.012)$. On the other hand, there are no significant differences in goal commitment between the two pro-environmental value statement conditions for those who have the goal imposed ( $\mathrm{F}=0.59$; onetailed $\mathrm{p}=0.224)$. These results are consistent with the central argument of this study that a pro-environmental value statement acts as an effective informal control for stimulating managers to act in compliance with the prioritized values by reducing their commitment to the financial goal, but only when the profit goal is participative.

The differences in commitment to the profit goal are also examined for the levels of goal setting when the pro-environmental value statement is present versus absent. Consistently with the arguments of this study, in the presence of the pro-environmental value statement, goal commitment is significantly lower when the goal is participative versus imposed ( $\mathrm{F}=2.44$; one-tailed $\mathrm{p}=0.062$ ). In turn, consistently with the literature on budgetary participation [e.g., Chong et al. (2006) and Maiga (2005)], in the absence of the value statement, the commitment is greater for a participative goal than for an imposed one $(F=2.96$; one-tailed $p=0.045)$. In general, the results suggest that participation in setting the profit goal increases the commitment to that goal when the pro-environmental value statement is absent, giving additional support to $\mathrm{H}_{1}$.

\section{3 $\mathrm{H}_{2}$ : Effects on Environmental Compliance}

The second hypothesis predicts that a lower level of commitment to the profit goal increases environmental compliance, but only when the managers participate in the goal-setting $\left(\mathrm{H}_{2}\right)$. To test $\mathrm{H}_{2}$, a logistic regression is run with environmental compliance as the dependent variable and the level of commitment as an independent variable. Again, social value orientation is included as a control variable. Untabulated results indicate that goal commitment has a negative and statistically significant effect on environmental compliance $(z=-2.26$; onetailed $\mathrm{p}=0.012)$. In particular, of the 49 participants with commitment below the median (0.29), 63.3\% opt for environmental compliance; in turn, of the 54 with commitment above the median, $50 \%$ opt for environmental compliance. Together, these results suggest that the participants with lower levels of commitment to the profit goal are also those that most opt for environmental compliance, thus offering support to $\mathrm{H}_{2}$.

\subsection{Mediation Analysis}

The central argument of this study suggests that a proenvironmental value statement increases environmental compliance for managers whose profit goal is participative because these managers reduce their commitment to that goal. Depending on the extent to which that argument is valid, unlike when the pro-environmental value statement is absent, the participants whose goal is participative are expected to reduce their commitment and thus increase their environmental compliance in the presence of the pro-environmental value statement. So, goal commitment is expected to be a mediator of the effect of the pro-environmental value statement on environmental compliance, but only when the goal is participative.

To verify this possibility, an analysis is conducted with a structural equations modelling (Church et al., 2019). Figure 2 presents the results of the model. It is confirmed that the model is adequate with the Tucker-Lewis index (1.00), the root mean square error of approximation $(0.00)$, and the comparative fit index (1.00). Consistently with the arguments of this study and $\mathrm{H}_{1}$, for the participants with a participative goal, the pro-environmental value statement has a statistically significant effect on their commitment to the profit goal, with less commitment in the presence versus in the absence of the value statement ( $p=0.019$, one-tailed, link 1$)$. In turn, the relationship between the value statement and goal commitment is not statistically significant ( $\mathrm{p}=0.242$, one-tailed, link 1 ) when the goal is imposed. 


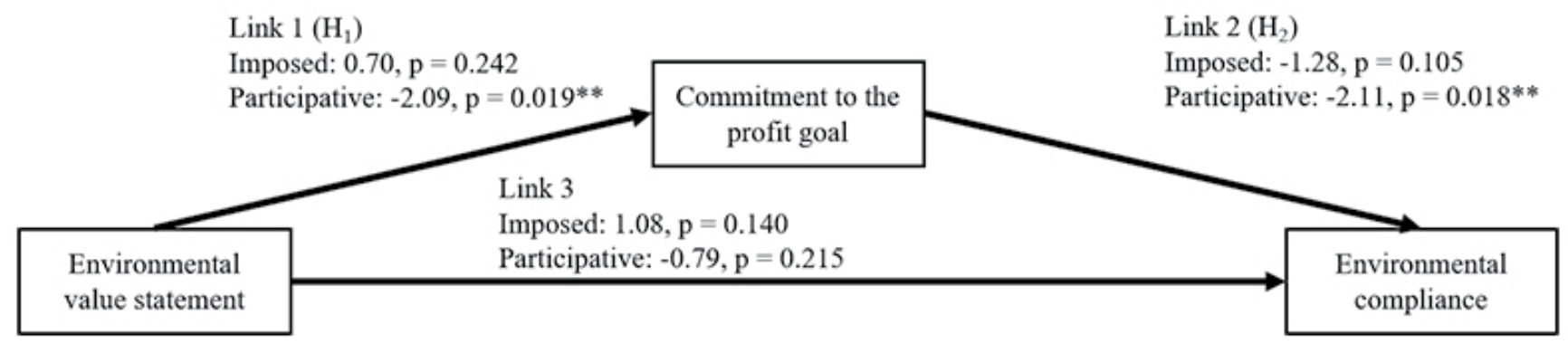

Figure 2 Mediation analysis

** = significant at 5\%.

Source: Elaborated by the author.

Consistent with the arguments of this study and $\mathrm{H}_{2}$, commitment has a negative and statistically significant effect on environmental compliance when the goal is participative ( $\mathrm{p}=0.018$, one-tailed, link 2$)$, so that lower commitment to the profit goal increases environmental compliance. In turn, when the goal is imposed, the relationship between commitment and environmental compliance is not statistically significant ( $\mathrm{p}=0.105$, one-tailed, link 2). Together, the results support the mediation argument in which a pro-environmental value statement signals the behaviors considered appropriate in a particular context and thus makes managers behave consistently with the prioritized environmental values by reducing their commitment to the profit goal and adopting pro-environmental behaviors, but only when the profit goal is participative.

Figure 2 also indicates that the results of link 3 are consistent with the expectations of the study that the effect of a value statement on environmental compliance tends to occur via the commitment to achieving financial goals. Whether for a participative or imposed goal, the pro-environmental value statement does not have a direct effect on environmental compliance. This result suggests total mediation, in which the effect of the pro-environmental value statement occurs through the commitment to the profit goal, and only when the goal is participative. In general, evidence is obtained that is consistent with the central argument of this study, that a pro-environmental value statement is an effective informal control, but only for managers whose profit goal is participative, since the values prioritized in the statement stimulate those managers to reduce their commitment to the profit goal and thus increase their environmental compliance. In turn, for managers whose profit goal is imposed, the pro-environmental value statement is not effective in reducing their commitment to the profit goal and thus stimulating environmental compliance.

\section{CONCLUSION}

In the context of a decentralized organization, this study examines whether a pro-environmental value statement is an effective informal control for stimulating pro-environmental behaviors by affecting middle-level managers' commitment to a profit goal. The results indicate that the presence of a pro-environmental value statement reduces their goal commitment, but only when there is participation in the goal-setting. In turn, less goal commitment increases environmental compliance. These findings are consistent with the central argument of this study that a pro-environmental value statement stimulates managers whose profit goal is participative to reduce their commitment to achieving that goal in favor of actions consistent with the values prioritized in the statement, that is, in favor of pro-environmental behavior, even if this implies not obtaining personal benefits. However, for managers with an imposed goal, a pro-environmental value statement does not stimulate appropriate behaviors.

The results of this study have implications for the research and practice. The research on management control has increasingly focused its attention on the behavioral effects of a value statement (Andrejkow et al., 2019; Kachelmeier et al., 2016). This study contributes to this emerging line of research by indicating when and how a pro-environmental value statement is effective at stimulating pro-environmental behavior. Consistently with previous studies, it is indicated that the behavioral effects of the value statement depend on the presence of formal controls (Kachelmeier et al., 2016). In particular, the effectiveness of a pro-environmental value statement 
as an informal control for stimulating pro-environmental compliance depends on the participation in setting the profit goal. Moreover, this study adds to the literature by indicating that commitment to the profit goal acts as a mediator variable of the effect of the pro-environmental value statement on pro-environmental behavior.

The results of this study also contribute to the research on management control that emphasizes the role of participation in setting financial goals in the commitment to those goals. Previous studies typically indicate the existence of positive effects of greater participation on commitment (Chong et al., 2006; Maiga, 2005). In turn, the literature on motivation at work suggests that the effects of participation on commitment depend on the context (Klein \& Joseph, 2013; Locke et al., 1988). The results of this study confirm that participation in setting financial goals has a positive effect on the level of commitment to these goals, but only when there is no pro-environmental value statement. In the presence of an environmental value statement, the managers deviate from the financial goal by reducing their commitment to that goal in favor of actions that are consistent with the values prioritized in the statement. Thus, the results of this study suggest that to understand the behavioral effects of participation in financial goal setting, it is important to consider whether a value statement is present or not, as well as if the values prioritized in the statement are conflicting or not with the financial goal.

The results of this study also offer practical contributions. With the aim of stimulating appropriate behaviors, organizations typically use formal controls (Andrejkow et al., 2019; Berry et al., 2009). Although they incentivize appropriate behaviors in certain contexts, these controls tend to be ineffective for stimulating prosocial behavior (Christ et al., 2008; Tenbrunsel \& Messick, 1999). In organizations for which prosocial and, particularly, pro-environmental behaviors are important, this study indicates that a value statement can be an effective informal control mechanism for stimulating appropriate behaviors among middle-level managers who have decision-making autonomy. Recent examples from the literature on the use of formal controls and the potential role that communication from top executives can have to stimulate appropriate behaviors are reported in the case of the environmental disasters caused by Vale S.A. (Godoy et al., 2019). In summary, decentralized organizations can benefit from communicating a pro-environmental value statement to stimulate pro-environmental behaviors, providing the managers participate in the goal setting.

This study has limitations that represent opportunities for future research. The context of this study suggests a decentralized decision-making process in which the middle-level managers have autonomy to decide how the resources are allocated. In centralized contexts, the managers may not have the same autonomy to deviate from fulfilling the financial goals in favor of pro-environmental behaviors. Equally, the context of this study emphasized a sanctioning system characterized as weak. However, previous evidence shows that a strong sanctioning system can stimulate appropriate behaviors (Tenbrusel \& Messick, 1999). Whether in centralized organizations or in contexts with a strong sanctioning system, it is not evident whether a value statement can be an effective informal control for inducing appropriate behaviors, even if the goal setting is participative. Future studies could verify whether in centralized organizations exposed to stronger sanctioning systems a value statement would play a different role, such as maintaining a favorable reputation for different groups in society, including customers and investors (Brammer \& Millington, 2005).

A second limitation of this study is that it considers a value statement that prioritizes a single performance dimension, in this case respect and appreciation for the environment. The inclusion of a single prioritized value avoids ambiguity regarding which value is more relevant and enables the behavioral effects of the value statement to be verified in a more controlled way. However, in practice, organizations can include multiple values in their value statements. In these cases, the presence of perceived goal conflict tends to be greater, with the managers being less certain about which goal to prioritize when making resource allocation decisions (Andrejkow et al., 2019). Future studies could examine whether a value statement can be an effective informal control for stimulating proenvironmental behaviors when multiple dimensions of performance are prioritized (e.g., environmental and financial).

A third limitation is that the context of this research includes a single type of formal control and examines whether the behavioral effects of a value statement depend on that formal control. Again, the inclusion of a single formal control enables greater experimental control and thus contributes to the internal validity of the study. However, in practice, multiple formal controls are simultaneously present (e.g., subjectivity in the performance evaluation and level of goal difficulty), as well as informal ones (e.g., tone of voice of the chief executive officer and mission and vision statements). Future studies could gather data on multiple organizations, with different management controls, with the aim of verifying whether value statements would be effective as control mechanisms in the presence of multiple alternative controls. 
Finally, the participants in this study are recruited via MTurk, which means that they may have different cultural origins and be derived from different nationalities. Since there is not a variable controlling for participants' nationality, attention needs to be paid when interpreting the results of this study, as they may have been affected by the participants' cultural differences, even in terms of the applicability of those results to the Brazilian context, which has its own cultural specificities. Even though not controlled for cultural differences, the results of this study suggest that on average the presence of a pro-environmental value statement can be an effective informal control for stimulating appropriate behaviors, but only for managers who participate in the goal setting.

\section{REFERENCES}

Akinyele, K. O., Arnold, V., \& Sutton, S. G. (2020). Wording and saliency matter: The impact of incentive system and organizational value statement on employees' performance. Behavioral Research in Accounting, 32(1), 101-118.

Andrejkow, J., Berger, L., \& Guo, L. (2019). Addressing goal conflict - The effects of conscious and nonconscious goal priming on performance in multidimensional tasks [Working Paper]. Social Science Research Network. https://papers.ssrn.com/ sol3/papers.cfm?abstract_id=3234092

Arnold, M. C. (2015). The effect of superiors' exogenous constraints on budget negotiations. The Accounting Review, 90(1), 31-57.

Bansal, P., \& Roth, K. (2000). Why companies go green: A model of ecological responsiveness. Academy of Management Journal, 43(4), 717-736.

Berry, A. J., Coad, A. F., Harris, E. P., Otley, D. T., \& Stringer, C. (2009). Emerging themes in management control: A review of recent literature. The British Accounting Review, 41(1), 2-20.

Brammer, S., \& Millington, A. (2005). Corporate reputation and philanthropy: An empirical analysis. Journal of Business Ethics, 61(1), 29-44.

Buchheit, S., Dalton, D. W., Pollard, T. J., \& Stinson, S. R. (2019). Crowdsourcing intelligent research participants: a student versus MTurk comparison. Behavioral Research in Accounting, 31(2), 93-106.

Buhrmester, M., Kwang, T., \& Gosling, S. D. (2016). Amazon's Mechanical Turk: A new source of inexpensive, yet highquality data? In A. E. Kazdin (Ed.). Methodological issues and strategies in clinical research ( $4^{\text {th }}$ ed.) (pp. 133-139). American Psychological Association.

Chang, G. S. Y., \& Lorenzi, P. (1983). The effects of participative versus assigned goal setting on intrinsic motivation. Journal of Management, 9(1), 55-64.

Chatman, J. A. (1991). Matching people and organizations: Selection and socialization in public accounting firms. Administrative Science Quarterly, 36(3), 459-484.

Chong, V. K., \& Chong, K. M. (2002). Budget goal commitment and informational effects of budget participation on performance: A structural equation modeling approach. Behavioral Research in Accounting, 14(1), 65-86.

Chong, V. K., Eggleton, I. R., \& Leong, M. K. (2006). The multiple roles of participative budgeting on job performance. Advances in Accounting, 22, 67-95.
Christ, M. H., Sedatole, K. L., Towry, K. L., \& Thomas, M. A. (2008). When formal controls undermine trust and cooperation. Strategic Finance, 89(7), 39-44.

Church, B. K., Jiang, W., Kuang, X., \& Vitalis, A. (2019). A dollar for a tree or a tree for a dollar? The behavioral effects of measurement basis on managers' CSR investment decision. The Accounting Review, 94(5), 117-137.

Clark, C. F., Kotchen, M. J., \& Moore, M. R. (2003). Internal and external influences on pro-environmental behavior: Participation in a green electricity program. Journal of Environmental Psychology, 23(3), 237-246.

Coelho, J. A. P. D. M., Gouveia, V. V., \& Milfont, T. L. (2006). Valores humanos como explicadores de atitudes ambientais e intenção de comportamento pró-ambiental. Psicologia em Estudo, 11(1), 199-207.

Collis, D. J., \& Rukstad, M. G. (2008). Can you say what your strategy is? Harvard Business Review, 86(4), 82-90.

Dawes, R. M. (1980). Social dilemmas. Annual Review of Psychology, 31(1), 169-193.

Dawes, R. M., \& Messick, D. M. (2000). Social dilemmas. International Journal of Psychology, 35(2), 111-116.

Dhaliwal, D. S., Li, O. Z., Tsang, A., \& Yang, Y. G. (2011). Voluntary nonfinancial disclosure and the cost of equity capital: The initiation of corporate social responsibility reporting. The Accounting Review, 86(1), 59-100.

Dhaliwal, D. S., Radhakrishnan, S., Tsang, A., \& Yang, Y. G. (2012). Nonfinancial disclosure and analyst forecast accuracy: International evidence on corporate social responsibility disclosure. The Accounting Review, 87(3), 723-759.

Ferreira, A., \& Otley, D. (2009). The design and use of performance management systems: an extended framework for analysis. Management Accounting Research, 20(4), 263-282.

Fisher, J. G., Peffer, S. A., \& Sprinkle, G. B. (2003). Budget-based contracts, budget levels, and group performance. Journal of Management Accounting Research, 15(1), 51-74.

Fleischer, A., Mead, A. D., \& Huang, J. (2015). Inattentive responding in MTurk and other online samples. Industrial and Organizational Psychology, 8(2), 196-202.

Godoy, D., Desidério, M., Flach, N., \& Vieira, R. (2019, 20 de março). Os sete pecados da Vale. Exame.

Guth, W. D., \& MacMillan, I. C. (1986). Strategy implementation versus middle management self-interest. Strategic Management Journal, 7(4), 313-327. 
Kachelmeier, S. J., Thornock, T. A., \& Williamson, M. G. (2016). Communicated values as informal controls: Promoting quality while undermining productivity? Contemporary Accounting Research, 33(4), 1411-1434.

Klein, H. J., \& Joseph, T. C. (2013). Goal commitment. In E. A. Locke \& G. P. Latham (Eds.). New developments in goal setting and task performance (pp. 89-113). Routledge.

Lam, S. S., Chen, X. P., \& Schaubroeck, J. (2002). Participative decision making and employee performance in different cultures: The moderating effects of allocentrism/ idiocentrism and efficacy. Academy of Management Journal, 45(5), 905-914.

Latham, G. P., \& Locke, E. A. (1991). Self-regulation through goal setting. Organizational Behavior and Human Decision Processes, 50(2), 212-247.

Locke, E. A., Latham, G. P., \& Erez, M. (1988). The determinants of goal commitment. Academy of Management Review, 13(1), 23-39.

Locke, E. A., Shaw, K. N., Saari, L. M., \& Latham, G. P. (1981). Goal setting and task performance: 1969-1980. Psychological Bulletin, 90(1), 125.

Maclagan, P. (1999). Corporate social responsibility as a participative process. Business Ethics: A European Review, 8(1), 43-49.

Maiga, A. S. (2005). Antecedents and consequences of budget participation. In M. J. Epstein \& J. Y. Lee (Eds.). Advances in management accounting (Vol. 14) (pp. 211-231). Elsevier.

Malmi, T., \& Brown, D. A. (2008). Management control systems as a package - Opportunities, challenges and research directions. Management Accounting Research, 19(4), 287-300.

Marginson, D. (2009). Value systems as a mechanism for organizational change. Journal of Accounting \& Organizational Change, 5(1), 7-34.

Merchant, K. A., \& Van der Stede, W. A. (2012). Management control systems performance measurement, evaluation and incentives ( $3^{\text {rd }}$ ed.). Financial Times/Prentice Hall.

Nouri, H., \& Parker, R. J. (1998). The relationship between budget participation and job performance: The roles of budget adequacy and organizational commitment. Accounting, Organizations and Society, 23(5-6), 467-483.

Ones, D. S., Wiernik, B. M., Dilchert, S., \& Klein, R. (2015). Pro-environmental behavior. In G. Hardiess et al. (Eds.). International encyclopedia of the social \& behavioral sciences (2a. ed.) (pp. 82-88). Elsevier.

Ouchi, W. G. (1979). A conceptual framework for the design of organizational control mechanisms. Management Science, 25(9), 833-848.

Paillé, P., \& Boiral, O. (2013). Pro-environmental behavior at work: Construct validity and determinants. Journal of Environmental Psychology, 36, 118-128.
Rodgers, W., Söderbom, A., \& Guiral, A. (2015). Corporate social responsibility enhanced control systems reducing the likelihood of fraud. Journal of Business Ethics, 131(4), 871-882.

Santos, B. F. (2017, 17 de janeiro). Consumidores querem empresas preocupadas com o meio ambiente. Veja. https://veja.abril.com.br/economia/consumidores-queremempresas-preocupadas-com-o-meio ambiente/

Schwartz, S. H. (1992). Universals in the content and structure of values: Theoretical advances and empirical tests in 20 countries. In M. P. Zanna (Ed.), Advances in experimental social psychology (Vol. 25) (pp. 1-65). Academic Press.

Simons, R. (1995). Levers of control. Harvard Business School Press.

Spector, P. E. (1986). Perceived control by employees: A metaanalysis of studies concerning autonomy and participation at work. Human Relations, 39(11), 1005-1016.

Spreitzer, G. M. (1996). Social structural characteristics of psychological empowerment. Academy of Management Journal, 39(2), 483-504.

Steg, L., \& Vlek, C. (2009). Encouraging pro-environmental behaviour: An integrative review and research agenda. Journal of Environmental Psychology, 29(3), 309-317.

Tamayo, A. (1998). Valores organizacionais: Sua relação com satisfação no trabalho, cidadania organizacional e comprometimento afetivo. Revista de Administração, 33(3), 56-63.

Tenbrunsel, A. E., \& Messick, D. M. (1999). Sanctioning systems, decision frames, and cooperation. Administrative Science Quarterly, 44(4), 684-707.

Van der Kolk, B., Ter Bogt, H. J., \& Van Veen-Dirks, P. M. (2015). Constraining and facilitating management control in times of austerity: Case studies in four municipal departments. Accounting, Auditing \& Accountability Journal, 28(6), 934-965.

Van Lange, P. A., De Bruin, E., Otten, W., \& Joireman, J. A. (1997). Development of prosocial, individualistic, and competitive orientations: Theory and preliminary evidence. Journal of Personality and Social Psychology, 73(4), 733.

Verplanken, B., \& Holland, R. W. (2002). Motivated decision making: Effects of activation and self-centrality of values on choices and behavior. Journal of Personality and Social Psychology, 82(3), 434.

Webb, R. (2004). Managers' commitment to the goals contained in a strategic performance measurement system. Contemporary Accounting Research, 21(4), 925-958.

Wentzel, K. (2002). The influence of fairness perceptions and goal commitment on managers' performance in a budget setting. Behavioral Research in Accounting, 14(1), 247-271.

Wessling, K. S., Huber, J., \& Netzer, O. (2017). MTurk character misrepresentation: Assessment and solutions. Journal of Consumer Research, 44(1), 211-230. 